\title{
Separating the Biased Perceptions from Lack of Knowledge on Entrepreneurship Through a Diagnostic Instrument: LEDI
}

\author{
Elif KALAYCI \\ Atılım University \\ Faculty of Economics and Administrative \\ Sciences, Ankara, Turkey \\ orcid.org/0000-0001-6658-0595 \\ elif.kalayci@atilim.edu.tr
}

\author{
Ceyhan ÇİĞDEMOĞLU \\ Atılım University \\ Faculty of Education Sciences \\ Ankara, Turkey \\ orcid.org/0000-0001-5389-5790 \\ ceyhan.cigdemoglu@atilim.edu.tr
}

\begin{abstract}
Students of entrepreneurship either have 'biased perceptions' and/or they lack knowledge. The literature states that biased perceptions can have lasting effect even after the training (von Graevenitz, et.al, 2010). Lack of knowledge hinders the decision making of nascent entrepreneurs when they rely on personal opinions or past experiences as heuristics derived from small samples or non-random samples. Currently entrepreneurship education is not designed to address the impact of biased perceptions and lack of knowledge. There is a need to separate biased perceptions from 'lack of knowledge' so that entrepreneurship training could be implemented on a more tailored manner. It is the goal of this paper to devise such an instrument in the lean start up context which is a widely used model of entrepreneurship training. The proposed instrument is tested on a convenience-based sample composed of 212 people. Employment of a three-tiered instrument in this context is a first of its kind. Knowledge or lack of knowledge is checked in the first tier, relevant reasoning is assessed in the second and certainty is evaluated in the third tier.
\end{abstract}

Keywords: Entrepreneurship, diagnostic instrument, test development

\section{Introduction}

Entrepreneurship is seen as a significant contributor to national prosperity, a solution to problems such as economic slowdown (Matlay, 2005) and unemployment (Audretsch, Grilo, \& Thurik, 2011). Therefore, entrepreneurship education has been included in the public policy measures in both developed and developing countries (Matlay, 2005). Notwithstanding the agreed upon significance of entrepreneurship education, in the literature there is no consensus on the methods and content of courses on entrepreneurship (Mwasalwiba, 2010, Blenker et.al., 2012).

In a review of entrepreneurship education, Mwasalwiba (2010) reports that most entrepreneurship education incorporates knowledge on what entrepreneurship is and how a venture is formed. Although advancement in teaching techniques such as Lean Startup (Ries, 2011) has been introduced in entrepreneurship education, most course 
content is rather generic. Middleton and Donnellon (2014) object to this generic nature of entrepreneurship education claiming 'learning theory tells us that the knowledge for actually taking entrepreneurial action requires the engagement of the individual .....' (Middleton and Donnellon, 2014, p193). However, in order to 'engage the individual', course designers need to identify the pre-education beliefs of the individuals on entrepreneurship (Arennius and Minniti, 2005). While the significance of pre-education beliefs of students on post education entrepreneurial actions is established in the literature (von Graevenitz, et.al., 2010), lack of knowledge on new venture founding also needs to be addressed. Aldrich and Ruef (2006, p.81) claim that 'When confronted with a lack of knowledge sharing, many nascent entrepreneurs will tend to overgeneralize from personal experience' which seriously hinders their chances of success. Therefore, identifying 'the lack of knowledge' and 'biased perceptions' of students of entrepreneurship can improve the content and the design of entrepreneurship courses. Our proposed tool fills this gap.

\section{Literature Review}

Research on entrepreneurship education assumes that students who take entrepreneurship courses do so randomly. However, there may be a self-selection bias because students may be choosing these courses with the intention of starting a venture (Noel, 2002). Ex-post education intentions of these students may not change due to entrepreneurship education because they may be affected from ex-ante intentions. As a matter of fact, von Graevenitz, et.al. (2010) indicates that students' ex-ante intentions are strongly correlated with ex-post intentions after entrepreneurship education.

Thus, it is evident in the literature that the ex-ante intentions of entrepreneurship students need to be scrutinized in order to better cater their needs. When one questions what affects the intentions of people regarding a certain form of action, the theory of planned behaviour (Ajzen, 1991) proposes three beliefs. The first one is behavioural beliefs or attitudes toward behaviour. Attitudes could be either positive or negative regarding the target behaviour. Second is the normative beliefs which are based on subjective norms. Subjective norms could be the disapproval or approval of the social environment, such as that of friends, family and other significant groups. The opinion of the surrounding environment affects whether the individual should engage in the target behaviour. Third is the control beliefs which constitute the basis of perceptions on behavioural control. Perceived behavioural control (PBC) refers to a perceived ease or hardship as far as carrying out the target behaviour is concerned. Intention is directly affected by attitude and subjective norms whereas PBC directly affects behaviour and indirectly affects behaviour over intentions. At times when the individual feels a high degree of control over behaviour, intention alone can be a sufficient predictor of behaviour. On the other hand, when the individual does not have a high degree of control over behaviour, $\mathrm{PBC}$ directly affects actual behaviour and indirectly through intention (Ajzen, 1991).

In the context of entrepreneurship, this theory has been empirically tested on students (Varamaki et.al. 2016). While some find attitude, subjective norms and perceived behavioural control as significant determinants of entrepreneurial intention (Khan et. al., 2016), others report perceived behavioural control affects intention more than attitude and subjective norms do (Kautonen et. al. 2013, Zhang et. al 2015). Others find subjective norms have a significant negative effect (Shook and Bratianu, 2008) or no effect at all on entrepreneurial intention (Krueger et. al., 2000). When the theory has 
been tested on non-students, it is found that intention and perceived behavioural control are significant predictors of entrepreneurial behaviour (Obschonka et.al., 2012). In their study to check the robustness of TPB Kautonen et.al., (2015, p. 668) report that

".....attitude, subjective norms, and PBC jointly explain $59 \%$ of the variation in intention...and concerning the antecedents of intentions we find that subjective norms have the strongest effect, which is contrary to previous research that tends to find subjective norms to be the weakest predictor of entrepreneurial intentions (Schlaegel and Koenig, 2012)"

While Kautonen et. al. (2015) attribute this finding to the frequent employment of student samples in the literature, it is apparent that there is need to further examine the antecedents of intentions as far as entrepreneurship is concerned. Regarding the affect of perception on entrepreneurial behaviour, Arennius and Minniti (2005, p.243) report the following:

"across all countries and across genders, perceptual variables and, in particular, the perception that individuals have of their own entrepreneurial abilities are very important. Unfortunately, perceptual variables reflect subjective perceptions rather than objective conditions. As a result, they are likely to be biased. There exists some evidence that distortions in perceptions are common among individuals in general, and among entrepreneurs in particular (Cooper et al., 1988; Busenitz and Barney 1997). The importance of perceptual variables, and their associated bias, in the decision to start a new business may explain some of the observable inconsistencies between expected and actual returns to entrepreneurship and entrepreneurial decisions found in the literature (Hamilton, 2000) as well as the fact that many new businesses fail shortly after inception (Dunne et al., 1988, Geroski, 1995)".

Another factor that contributes to subjective perceptions, is lack of knowledge. Kahneman et. al. (1982) state that people tend to make decisions based on small or nonrandom samples while ignoring the unreliability or unrepresentativeness of small samples. Studying the founders of 124 startups in comparison to 95 managers of two large corporations, Busenitz and Barney (1997) report that entrepreneurs tend to use rules of thumbs or their own opinion more than the managers. Such behaviour is more prone with entrepreneurs that come from families where either one or two parents were entrepreneurs or were working as managers (Aldrich et. al. 1998). Although Busenitz and Barney (1997) claim using heuristics or own opinion in decision making saves time for entrepreneurs, they may also lead to failure if deduced from unrepresentative samples.

As both 'biased perceptions' and 'lack of knowledge' are critical as far as entrepreneurial behaviour is concerned (Kollinger and Minniti, 2006), it is essential to study these phenomena particularly for designing adequate training material for students of entrepreneurship.

Given that entrepreneurship is a vast area, one needs to define a region with predetermined boundaries to identify the topics in order to examine students' perceptions. The 'Lean Startup approach (LSA)' of Ries (2011) which is a novel method to facilitate entrepreneurial learning serves this purpose covers the main aspects of business model generation. LSA defines a start-up as 'a human institution designed to create a new product or service under conditions of extreme uncertainty' Ries (2011, p.37). There are three main principles of this approach distinguishing it from the traditional enterprise planning. The first principle is that founders should summarize 
their hypothesis. Secondly, they should go and ask feedback on those hypotheses from potential customers in order to come up with a minimum viable product (MVP) which is a basic working model of the product-in-progress. Thirdly, these feedbacks should be incorporated into the MVP and new rounds of hypothesis testing should be performed with the potential users so that time can be saved in the development of the product (Blank, 2013).

In a web-based entrepreneurship course titled "How to Start a Start-up", Steve Blank (2016) introduces the Business Model Canvas and underlines some issues where students have pre-conceived perceptions. When these issues are considered together with the recommendation of Kautonen et. al. (2015, p.669) calling for an 'increase in the level of specificity and assessment of all TPB constructs at the level of various gestation activities ..... such as developing a product, conducting market research, writing a business plan and arranging finance', the focus and the level of specificity of this paper emerge. The topics of concern in this paper are equity distribution, the goal of being an entrepreneur, approach to an innovative business idea, development of ideal product/service, competition with an existing product, listening to others' opinion in the founding phase, prospects of a start-up that secured high sales volume, job definition of an entrepreneur and the use of a prototype.

While the literature claims 'biased perceptions' and 'lack of knowledge' need to be taken into account when evaluating the impact of perceptions on entrepreneurial intentions (Arennius and Minniti, 2005; Aldrich and Ruef,2006), no tool exists to identify and distinguish them. The work of Linan and Chen (2009) is an instrument to measure entrepreneurial intentions but it does not take into account the biased perceptions. Since Linan and Chen (2009) does not specify a well-defined region regarding the sub-topics of entrepreneurship, their instrument happens to be more appropriate for evaluating 'aggregate entrepreneurial behaviour' and less appropriate to identify the individual perceptions. Yet, as the call in the literature is '..an increase in the specificity and assessment of TPB constructs at the level of various gestation activities'...(Kautonen et al. 2015), our goal is to propose a tool to identify the biased perceptions of entrepreneurship students who follow the LSA.

Recent research (Butt et.al. 2015) asserts that biased perceptions significantly affect the decision-making processes of entrepreneurs. Separating biased perceptions from lack of knowledge requires construction of a diagnostic instrument. This separation is essential because remedying biased perception requires different educational methods than ones used in constructing knowledge.

Assessing perceptions of nascent entrepreneurs usually include interviews (Liao and Welsch, 2008), open-ended response questions (Ogunsade and Obembe, 2016), structured surveys (Butt et.al., 2015) and case studies (Würmseher, 2017). Entrepreneurship education should aim to prevent entrepreneurs from making faulty start-up decisions. Thus, such education should specify nascent entrepreneurs' knowledge and preconceived biases. For the last few decades, diagnostic tools have been used as prominent assessment tools for data collection on biased perceptions in educational sciences. Starting with a multiple choice content question (first tier), the diagnostic tools introduces one more tier: the reason tier. Although two-tier instruments provide more information than other procedures in determining misconceptions, the presence of guessing may result in overestimation of knowledge level and biased perceptions. Hence, two-tier surveys do not separate lack of knowledge from biased 
perceptions. Therefore, an additional tier, which contains certainty of response, has been proposed to compensate for the likely weakness of the diagnostic tests (Pesman \& Eryilmaz, 2010).

To date, no study in the field of entrepreneurship has developed a three-tier instrument to identify biased perceptions and lack of knowledge. Therefore, whether an entrepreneur is knowledgeable or lacks knowledge or has biased perceptions could be determined through a three-tiered diagnostic tool. This study aims to construct and validate a reliable three-tiered diagnostic instrument to identify entrepreneurs' biased perceptions through the lean start-up (LS) lens.

\section{Method and Procedure}

\section{Development of a Three-tiered Instrument}

The framework described by Treagust (1988) was used as the underlying methodological procedure for the development of three-tier instrument to identify biased perceptions on LS concepts (LEDI, Lean Entrepreneurship Diagnostic Instrument). Initially concept boundaries related to LS were determined, then, based on the related literature, 8 generally accepted statements were identified (Table 1) and categorized as; initiation, development, and action stages of a business launch. Two experts of entrepreneurship education and two entrepreneurs reviewed the identified list of generally accepted knowledge statements. Content validation was established upon expert agreement and confirmation of the accuracy and appropriateness of the content for nascent entrepreneurs.

Table 1.Generally accepted statements and related items of the instrument

\begin{tabular}{|c|c|c|c|}
\hline & Statements & Reference & $\begin{array}{l}\text { Item } \\
\text { number }\end{array}$ \\
\hline \multirow{2}{*}{ 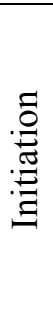 } & $\begin{array}{l}\text { The main goal of an entrepreneur is to make a profit } \\
\text { by creating value for customers. }\end{array}$ & $\begin{array}{l}\text { Osterwalder, A. } \\
\text { Pigneur Y, } \\
\text { Bernarda G., Smith } \\
\text { A.(2014) }\end{array}$ & Item2 \\
\hline & $\begin{array}{l}\text { An innovative business idea should be developed with } \\
\text { the intention of providing a value to potential } \\
\text { customers }\end{array}$ & $\begin{array}{l}\text { Cooper B and P. } \\
\text { Vlaskovits (2013), }\end{array}$ & Item3 \\
\hline \multirow{3}{*}{ 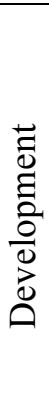 } & $\begin{array}{l}\text { Partners devote different amounts of time and effort to } \\
\text { the startup, therefore share distribution need not be } \\
\text { equal. }\end{array}$ & $\begin{array}{l}\text { Timmons (1979); } \\
\text { Hellman and } \\
\text { Wasserman }(2011)\end{array}$ & Item1 \\
\hline & $\begin{array}{l}\text { The ideal new product should be designed and } \\
\text { prototyped according to feedback from the potential } \\
\text { customers who are willing to help since the eventual } \\
\text { result satisfies their need or want }\end{array}$ & $\begin{array}{l}\text { Cooper B., P. } \\
\text { Vlaskovits (2013) }\end{array}$ & Item4-6 \\
\hline & $\begin{array}{l}\text { A prototype (first version of the product) should be a } \\
\text { working model of a 'work-in-progress' }\end{array}$ & Blank S. (2013) & Item9 \\
\hline \multirow[b]{3}{*}{.$\stackrel{0}{0}$} & $\begin{array}{l}\text { To compete with an existing product, an entrepreneur } \\
\text { should focus on the changed needs of the customers }\end{array}$ & Blank S (2006) & Item5 \\
\hline & $\begin{array}{l}\text { An entrepreneur may have to work on any job } \\
\text { requiring attention }\end{array}$ & Lazear E.P.(2004) & Item8 \\
\hline & $\begin{array}{l}\text { Cash collection takes time, and high sales revenue is } \\
\text { no shield against bankruptcy unless cash is collected } \\
\text { timely. }\end{array}$ & $\begin{array}{l}\text { Mungal and } \\
\text { Garbharran (2014) }\end{array}$ & Item7 \\
\hline
\end{tabular}


Next, twelve open-ended questions were prepared based on the knowledge statements and in line with the related literature to identify conceptions and biased perceptions. The first trial of the open-ended questionnaire was administered to 128 undergraduates enrolled in an entrepreneurship course. Analysis of the responses indicated difficulties in understanding the above-mentioned lean start-up concepts. Later, these knowledge statements and biased perceptions were used to construct the first version of the test. The biased perceptions used in the first and second tiers are provided in Table 2. The certainty of response termed as 'confidence about the response' (yes or no) is the third tier. Similar to the framework of Treagust (1988), the first part of each item is a multiple-choice content question having usually two to five choices. The first-tier includes generally accepted statements about the LS or biased perceptions on it. The second part includes possible reasons for the answers. The third part of each item is the certainty tier, which investigates whether the entrepreneurs are sure about their responses or not.

Table 2. Biased perceptions and their alternative sets.

\begin{tabular}{|c|c|}
\hline Biased Perceptions & Alternative sets \\
\hline $\begin{array}{l}\text { B1. A fair distribution of shares among partners is equal share } \\
\text { distribution. }\end{array}$ & 1.1.a, 1.2.a, 1.3.a \\
\hline $\begin{array}{l}\text { B2. Share distribution should not be an issue among founders who are } \\
\text { friends. }\end{array}$ & $\begin{array}{l}\text { 1.1.e, 1.2.e, 1.3.a } \\
\text { 1.1.c, 1.2.b, 1.3.a }\end{array}$ \\
\hline $\begin{array}{l}\text { B3. Share distribution depends on the amount of capital invested by } \\
\text { each partner. }\end{array}$ & 1.1.d, 1.2.c, 1.3.a \\
\hline B4. The main goal of an entrepreneur is to earn high income. & 2.1.a,2.2.b, 2.3.a \\
\hline $\begin{array}{l}\text { B5. The main goal of an entrepreneur is to work less than a full time } \\
\text { employee. }\end{array}$ & $\begin{array}{l}\text { 2.1.b., 2.2.a, 2.3.a } \\
\text { 8.1.b, 8.2.a,8.3.a }\end{array}$ \\
\hline $\begin{array}{l}\text { B6. The main goal of an entrepreneur is to be a boss, have a title and a } \\
\text { secretary. }\end{array}$ & $\begin{array}{l}\text { 2.1.c, 2.2.e, } 2.3 . \mathrm{a} \\
\text { 8.1.a, 8.2.b,8.3.a }\end{array}$ \\
\hline $\begin{array}{l}\text { B7. A previously un-attempted, innovative business idea is highly } \\
\text { likely to be a success. }\end{array}$ & 3.1.a, 3.2.f, 3.3.a \\
\hline B8. An innovative business idea must not be changed. & 3.1.c,3.2.b, 3.3.a \\
\hline $\begin{array}{l}\text { B9. An innovative business idea satisfying a need of the entrepreneur } \\
\text { should be turned into a start-up right away. }\end{array}$ & 3.1.d, 3.2.a, 3.3.a \\
\hline $\begin{array}{l}\text { B10. An innovative business idea must not be shared particularly with } \\
\text { an investor. }\end{array}$ & 3.1.e, 3.2.c, 3.3.a \\
\hline $\begin{array}{l}\text { B11. The ideal product/service must be produced before its customer } \\
\text { is found. }\end{array}$ & 4.1.a, 4.2.d, 4.3.a \\
\hline $\begin{array}{l}\text { B12. The ideal product/service is the one that provides an existing } \\
\text { feature for a lower price. }\end{array}$ & $\begin{array}{l}\text { 4.1.b, 4.2.a, } 4.3 . \mathrm{a} \\
\text { 5.1.a, 5.2.b, 5.3.a }\end{array}$ \\
\hline B13. The ideal product/service targets everyone as its customer. & 4.1.e, 4.2.b, 4.3.a \\
\hline $\begin{array}{l}\text { B14. One should use billboards as the fastest and most comprehensive } \\
\text { means of promotion. }\end{array}$ & 5.1.b, 5.2.d, 5.3.a \\
\hline $\begin{array}{l}\text { B15. To compete with an existing product, one needs to focus on one's } \\
\text { own goals rather than the actions of competitors. }\end{array}$ & 5.1.c, 5.2.a, 5.3.a \\
\hline $\begin{array}{l}\text { B16. An entrepreneur should follow the advice of his/her close circles } \\
\text { and not start a business if they say 'No, don't do it'. }\end{array}$ & 6.1.a, 6.2.d, 6.3.a \\
\hline $\begin{array}{l}\text { B17.An entrepreneur should rely on the 'surely, we will be your } \\
\text { customers' advice of his / her close circles and establish the start-up. }\end{array}$ & 6.1.c, 6.2.b,6.3.a \\
\hline $\begin{array}{l}\text { B18. A 'one time failed' entrepreneur, should not reattempt another } \\
\text { start-up. }\end{array}$ & 6.1.b, 6.2.a, 6.3.a \\
\hline
\end{tabular}




\begin{tabular}{|l|l|}
\hline $\begin{array}{l}\text { B19. An entrepreneur should pick his business idea among the popular } \\
\text { business ideas of the time. }\end{array}$ & 6.1.e, 6.2.c, 6.3.a \\
\hline B20. A start-up can collect its receivables one way or another. & 7.1a, 7.2.c, 7.3.a \\
\hline $\begin{array}{l}\text { B21. For a start-up, it is cheaper to acquire new customers than to keep } \\
\text { the current ones. }\end{array}$ & 7.1.b, 7.2.e, 7.3.a \\
\hline $\begin{array}{l}\text { B22. An entrepreneur puts all work in an order and carries each one } \\
\text { out, one after the other. }\end{array}$ & 8.1. d, 8.2.d, 8.3.a \\
\hline B23. Once a prototype is completed it is easy to sell the product. & 9.1.a, 9.2.a, 9.3.a \\
\hline $\begin{array}{l}\text { B24. A prototype should have all the features of the product to be } \\
\text { launched to the market. }\end{array}$ & 9.1.b, 9.2.c, 9.3.a \\
\hline B25. A prototype should reflect the cutting edge technology. & 9.1.c., 9.2.d, 9.3.a \\
\hline
\end{tabular}

Five entrepreneurs and three experts in entrepreneurship education examined the first version of the LEDI. This first version was piloted with 118 undergraduate engineering and business administration students. The data were entered to SPSS program (Statistical Package for the Social Sciences) and dichotomized based on the answer key. All correct answers to the first and second tier questions along with being certain (selecting 'Yes' in the third tier) were coded as 1 and 0 otherwise. To analyse the first version, Cronbach alpha reliability, item difficulties, and point biserial correlation coefficients were used. The item difficulty and point biserial correlation (the correlation of an item score with total score) indicated necessity of some revisions. After evaluating the item analysis, items 1 and 3 were revised completely, and items 7, $10,11,12$ were dropped since some had quite low point biserial correlation coefficient, indicating lacking in discriminating a knowledgeable person from an unknowledgeable. After a number of revisions, the second version of LEDI was developed with nine items. An example item of the final version of LEDI is shown in Figure 1.

\section{Figure 1. An example item of LEDI}

5.1 In order to compete with an existing product on the market,

a. The product must be sold at a price less than the existing one.

b. Billboards should be used as the fastest and most certain means of advertising.

c. One should focus on one's own goals rather than on what the competitors do.

d. Changed needs of the customers should be taken account of.

5.2 Which of the following is the reason for your answer to the previous question?

a. Complying with the business plan puts the entrepreneur ahead of its rivals because the business plan comprises 'absolutely certain' information.

b. Competitors can be left behind by pricing below that of competitors'.

c. One must know to what extend existing solutions meets the needs of the business.

d. To be known by as many people as possible increases sales; therefore advertising channels that can be seen by everyone should be used.

f. Other.

5.3. Are you confident in your answers to the previous two questions?
a. Yes
b. No 


\section{Sample}

The number of participants of the final version of the instrument was 212 . Through convenience sampling method, the instrument was administered to nascent entrepreneurs at a university. 119 participants were female, 103 were male. The age range was 18-34 years and participants were from faculties of engineering and business administration. LEDI was administered to volunteering undergraduates during the 20152016 academic year.

\section{Data Collection and Analysis}

The participants completed the instrument individually and anonymously in almost 15-20 minutes. Scale statistics were conducted to check whether the items functioned properly. Exploratory factor analysis was conducted to determine if appropriate factors loaded. Eight scores were calculated from responses, these are; the first-tier, both tier, total, certainty, lack of knowledge, biased first tier (B-first tier), biased both tier (B-both tiers), and biased all tiers (B-all tiers). Figure 2 summarizes how these scores were calculated (as described by Authors et al., 2012).

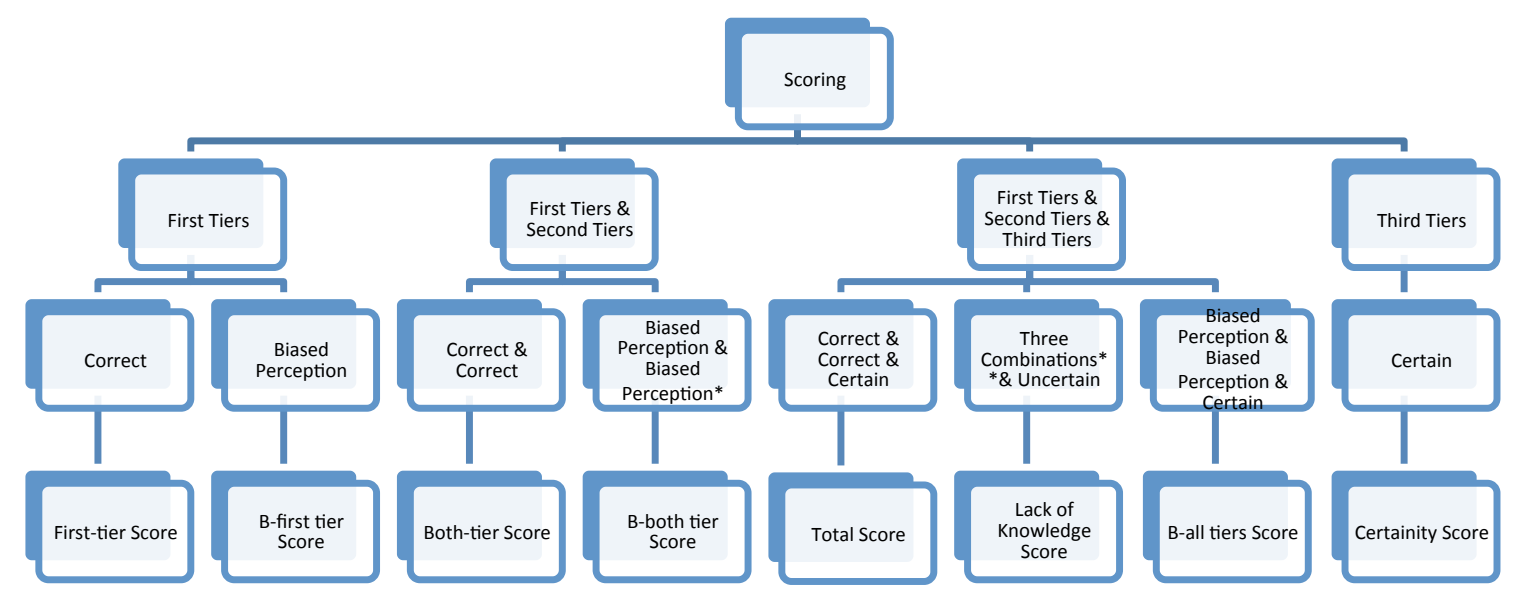

Figure 2 Coding and scoring procedure for LEDI. Note: The figure is adapted from Authors

**Biased perception in the second tier has to be consistent with biased perception in the first tier. Table 2 gives alternative sets of biased perceptions. **Three combinations are 'incorrect and correct', 'correct and incorrect', and 'incorrect and incorrect'.

Based on first-tier items of the LEDI, the first-tier score and B-first tier score were calculated. The first-tier score is the sum of a participants' correct responses to the first tiers of all items. Crocker and Algina (1986) describe item difficulty as the proportion of participants who answer an item correctly. Based on this, the proportion of nascent entrepreneurs who answered only the first tier of each item correctly was calculated as the difficulty level of the first-tier. The B-first tier score is the sum of participants' biased responses to only the first tiers of the alternative sets provided in Table 2. 
The both tier score and B-both tier score are calculated according to both the first and second tiers. Both-tier score is the sum of correct responses to both the first and the second tiers. Similar with the calculations done for the difficulty level of the one-tier test, difficulty level of the two-tier test is also computed. The B-both tier score is the sum of participants' responses which are biased both in the first and second tiers. The biased perception in the first-tier should be consistent with the biased perception in the second tier (as listed in the alternative sets; Table 2).

The total score and B-all tier score are calculated when all three tiers are taken into consideration. Therefore, total score is the sum of correct responses to both the first, second and the third tiers. The participants with high total scores have correct knowledge on the LS concepts. The difficulty level of the total scores means the difficulty level of the three-tier test. The B-all tier score is the sum of participants' biased responses to both the first and the second tiers, which are biased, and uncertain. In order to be counted as B-all tier score, the biased perception in the first tier must be followed by the related-biased perception in the second tier.

The Lack of knowledge score represents uncertainty regardless of holding correct or incorrect concepts to the first and/or second tiers. Hasan et al. (1999) states that 'irrespective of whether the answer was correct or wrong, a low certainty response index value indicates guessing, which, in turn, implies lack of knowledge' (p.3). In line with this, Odom and Barrow (2007) has stated that 'students who have low certainty in their answer combinations were possibly guessing and, therefore, had no understanding, or were confused about their understanding' (p.97). Therefore, we also treat the combinations of all three tiers (correct/incorrect/uncertain, incorrect/correct/uncertain, and incorrect/incorrect/uncertain) as 'lack of knowledge'. The last score is The Certainty Score, which is about only the third tier. The sum of each participant's 'Yes' response in this tier is called his/her certainty score.

All these response possibilities of the LEDI (first, second, and third tiers together) bring out five categories: Correct conceptualization, biased perceptions, false positives/ negatives, lucky guess, and lack of knowledge as Table 3 indicates.

Table 3. LEDI response possibilities

\begin{tabular}{llll}
\hline First tier & Second tier & Third tier & Categories \\
\hline Correct & Correct & Certain & Correct conceptualization \\
Correct & Incorrect & Certain & Biased perception (false positive) \\
Incorrect & Correct & Certain & Biased perception (false negative) \\
Incorrect & Incorrect & Certain & Biased perception \\
Correct & Correct & Uncertain & Lucky guess or lack of \\
& & & confidence \\
Correct & Incorrect & Uncertain & Lack of knowledge \\
Incorrect & Correct & Uncertain & Lack of knowledge \\
Incorrect & Incorrect & Uncertain & Lack of knowledge \\
\hline
\end{tabular}

*Note. The table is adapted from Authors et al. (2012)

False negatives and false positives are the terms used analogous to type I and type II errors in statistical hypothesis testing. False positive is an effect which is not actually present and false negative is failing to reveal an effect that is actually present. Hestenes and Halloun (1995) recommend that a correct answer along with a wrong reason (false positive), and a wrong answer followed by a correct reason (false negative) 
can be used to provide evidence for content validity in the development of diagnostic test. They state that minimization of these probabilities provide high validity. It is recommended that the probability of false negatives should be less than 10 percent. In the current study we treat the combinations of 'correct \& incorrect \& certain' and 'incorrect \& correct \& certain' as false positives and false negatives respectively and calculate their percentages.

\section{Results}

\section{Statistical Analysis of the LEDI}

In this part, the descriptive statistics of the final version of the LEDI have been summarized (Table 4). After the revision of the first version, the Cronbach alpha coefficient of the second version increased from 0.55 to 0.75 . This value is acceptable according to criterion-referenced tests (Crocker \& Algina, 1986). The mean score is 3.33 , the minimum value is 0 , the maximum is 8 . The item difficulty is the percentage of correct responses; a low number indicates a difficult item, a high number means that many of the respondents chose the correct answer.

Table 4: Item difficulty and discrimination indexes

\begin{tabular}{lll}
\hline Item Number & Item Difficulty Index $(\mathrm{p})$ & Item Discrimination Index $(\mathrm{r})$ \\
\hline 1 & 0.18 & 0.60 \\
2 & 0.55 & 0.38 \\
3 & 0.23 & 0.35 \\
4 & 0.30 & 0.47 \\
5 & 0.50 & 0.46 \\
6 & 0.50 & 0.52 \\
7 & 0.31 & 0.42 \\
8 & 0.57 & 0.45 \\
9 & 0.19 & 0.56 \\
Mean & 0.37 & 0.47 \\
\hline
\end{tabular}

The mean score of the LEDI (3.33 over 9) is an indication of its difficulty. The difficulty values of first tier is 0.59 , both tiers 0.39 , and of all three tiers 0.37 . As the numbers imply, answering one tier item is easier when compared to finding the reason for that along with being certain about it. A striking difference is observed between first and second tiers' difficulty, however, between second and third tier the difference is small. The first and the last items have lower difficulty values when compared to others. The first item includes one of the most prevalent biased perceptions which states that ' $\mathrm{A}$ fair distribution of shares among partners is equal share distribution'. Similarly, the last question on prototype's features includes a common biased perception that a prototype should capture all features of the final product. The point biserial correlation coefficients, indicating whether items function properly, are above 0.35 . Both difficulty and discrimination values are in desirable ranges for all items. The descriptive statistics of the LEDI indicates that it is a reliable instrument.

The validity issues of the LEDI are also investigated. Content validities are established based on expert opinions and the percentages of false positives and false negatives. According to Hestenes and Halloun (1995), if items of the test are clear and understandable, the knowledgeable participants would answer the test more correctly than the unknowledgeable ones. When these values are minimized, multiple-choice tests 
have greater validity. They state that false negatives should be less than $10 \%$, the LEDI has $4.54 \%$ for false negative and $5.7 \%$ for false positives. The construct validity of a test is related to its internal structure and requires statistical analysis such as correlation and factor analysis. Cataloglu (2002) suggests that if correlation between high scores and confidence is observed, it is an evidence of construct validity. The reason is that, participants having high scores are expected to be more confident with their answers. We carried a correlation analysis between both tier scores and certainty scores. A statistically significant positive correlation was found $(0.42$ at $\mathrm{p}: 0.01)$. We also conducted a factor analysis, but reasonable factors did not form.

\section{Nascent Entrepreneurs' Understanding of Lean Start-up Concepts}

The percentages of responses are provided in Table 5. Nascent Entrepreneurs' overall understanding which is indicated by correct response percentages, are very low for all three tiers.

Tablo 5. Percentages of the nascent entrepreneurs' responses

\begin{tabular}{|c|c|c|c|c|c|}
\hline \multirow[b]{2}{*}{$\begin{array}{l}\text { LEDI } \\
\text { item }\end{array}$} & \multicolumn{3}{|c|}{$\%$ Correct responses } & \multirow[b]{2}{*}{$\begin{array}{l}\% \text { Lack of } \\
\text { knowledge }\end{array}$} & \multirow[b]{2}{*}{$\begin{array}{l}\% \\
\text { Certainty }\end{array}$} \\
\hline & $\begin{array}{l}\text { Only-first } \\
\text { tiers }\end{array}$ & $\begin{array}{l}\text { Both-two } \\
\text { tiers }\end{array}$ & $\begin{array}{l}\text { All-three } \\
\text { tiers }\end{array}$ & & \\
\hline 1 & 42 & 18 & 18 & 8 & 91 \\
\hline 2 & 74 & 58 & 55 & 7 & 90 \\
\hline 3 & 76 & 25 & 23 & 11 & 87 \\
\hline 4 & 43 & 33 & 30 & 9 & 88 \\
\hline 5 & 59 & 52 & 50 & 8 & 89 \\
\hline 6 & 77 & 52 & 50 & 9 & 88 \\
\hline 7 & 42 & 34 & 31 & 27 & 69 \\
\hline 8 & 72 & 59 & 57 & 8 & 91 \\
\hline 9 & 42 & 20 & 19 & 22 & 77 \\
\hline Mean & & & & & \\
\hline$\%$ & 59 & 39 & 37 & 12 & 86 \\
\hline
\end{tabular}

The LEDI measures the biased perception in the LS approach. A noticeable difference is observed in certainty level of participants. Although, the mean percentage of all-three tier is 37 , the certainty score of test takers is quite high (86). This result could be attributable to the overconfidence observed in entrepreneurs. Koellinger et.al.(2007, p.504 ) report '.. we find nascent entrepreneurs to be more confident in their own skills than individuals who have been successfully in business for some times.... Confidence in one's own skills appears to be stronger among individuals in early stages of the entrepreneurial process, when the outcome of the business is still based on expectations.' Such result is corroborated by Pallier et al. (2002) who reveal that self-assessment in the cognitive domain produce overconfidence. Another surprising result is the mean of lack of knowledge percentage $(12 \%)$. This value implies that only a small number of participants have lack of knowledge. Such a finding could be attributable to the nascent entrepreneurs' frequent observing of entrepreneurial behaviour around themselves which enables them to have 'some' idea about entrepreneurship. As an explanation Minniti (2005; p.2) states '...by observing others, our potential entrepreneur acquires information and skills'. However, when all three tier score is examined it is explicit only $37 \%$ has correct perception on LS issues. The concepts of fair share distribution (Q1) and the concept of a prototype (Q9) are the 
least-known content area of the LEDI. In their study, Hellman and Wasserman (2012) indicate that other than field research, there is not much evidence about the structure of equity distribution for start-ups and therefore this is a less known area. Another area which is recently rechristened in the area of entrepreneurship by Blank (2013) under MVP is the concept of prototypes. Blank (2016) underlines the conviction of engineers to make the prototypes as closely as possible to the final product. His objection to this approach is new and thus less known. Blank (2013) argues an MVP should be used as a learning tool, so it should be as simple as possible to collect potential customer feedback. Yet, as indicated by the findings of the LEDI, nascent entrepreneurs do not know this.

The most well-known concepts are included in Q2, Q5, Q6, and Q8. These items are about goal of entrepreneurship, competition with an existing product, focus on changed needs of potential customers and job description of an entrepreneur. When correct answer percentages are examined, $57 \%$ gave desired response to Q8. This item is about an entrepreneur's job description being 'any job requiring attention'. Participants' perception are least biased about this issue. When first tier results are examined, $72 \%$ correctly perceive working on any job requiring attention, the difference between first and second tier is not very sharp, and almost no difference is observed between second and third tier. As observed in the other items, this indicates that if a participant's second tier score is high; then their third tier score is also high. Moreover, the confidence level is quite high almost for all items. Figure 3 summarizes correct answer percentages for all items.

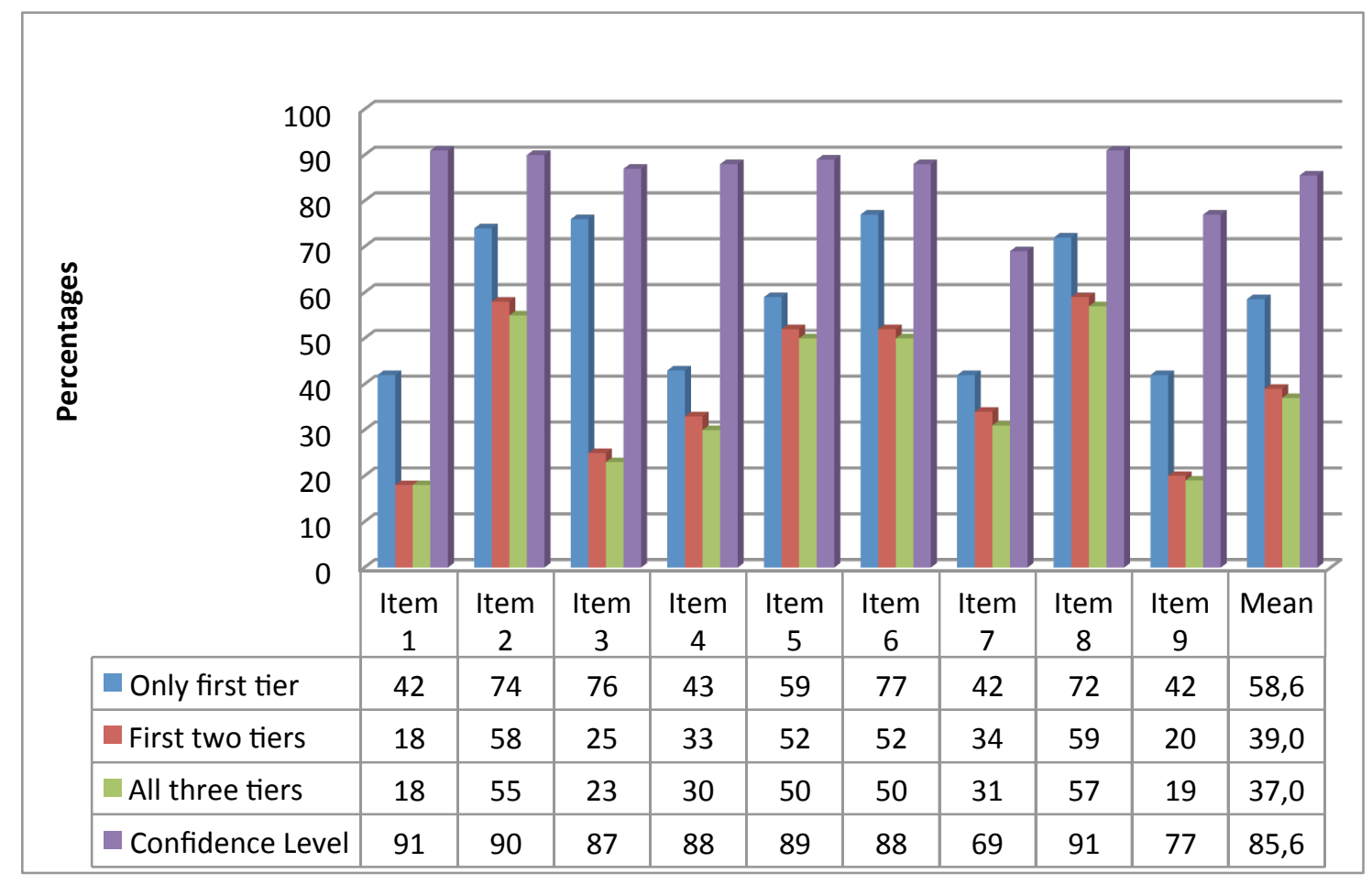

Figure 3. Percentages of correct responses

Next, the biased perceptions about LS concepts are examined (see Figure 4). The thirteenth biased perception (B13) is the most common one among the 25 biased perceptions in the LEDI. When the B-first tier scores are examined, $55 \%$ of the participants perceive that 'The ideal product/service targets everyone as its customer'. 
According to Blank (2016) most first-time entrepreneurs hold this biased perception. Therefore, in the LS approach, he underlines the importance of customer segmentation and correctly targeting the group that secures a match with the value proposition. The next prevalent biased perception is B25 which states 'A prototype should reflect the cutting edge technology'. Related to this bias Blank (2012) asserts MVP should be a primitive version of the idea to solve the pain of the customer and be flexible enough to allow changes in line with feedback from the potential customer. Similarly B1 and B24 are selected by $38 \%$ of the participants in the first tiers. In other words, $38 \%$ of the participants believe that 'a fair distribution of shares among partners is equal share distribution' and 'a prototype should have all the features of the product to be launched to the market' Hellman and Wasserman (2012) indicate that equal split of equity, hastily done at the beginning of the start-up, leads to lower growth and therefore warn against such practice yet. The mean percentage for biased perceptions in the B-first tier is 19 $\%$. Next, the second tier responses are investigated. These scores indicate if a biased perception is selected in the first tier and its reason is also selected among the alternatives provided in the second tier. The biased perception B1 is also the highest among the second tier scores, $26 \%$ of the nascent entrepreneurs selected this biased perception with its reason in the second tier. At the second tier, B1, B13, B25, and B4 are the four highest selected biased perceptions.

The least selected biases are given in B6, B7, B8, and B15, for these items B-both tier score is 0 , which means participants do not hold any biased perception on these issues. The mean percentages for B-both tier score is $4 \%$, which means $4 \%$ of test takers have biased perceptions. Totally, 22 of biased perceptions were selected by less than or equal to $10 \%$ of participants for the both tier scores. Next, the B-all tier responses are examined. B-both tiers score is almost close to B-all tiers scores. Only 4 biased perceptions (B1, B25, B13 and B4) are held by more than or equal to $9 \%$ of the nascent entrepreneurs. Biased perceptions; B6, B7, B8, B10, and B12 are not held by any participant. Three of these biases are included in item three (B7, B8 and B10), when correct responses related to this item is cross-checked from figure 3 , it is surprising that this item is one of the least known items. The other alternatives included in item 3 may cause such a result. The mean percentage for B-all tiers is $4 \%$, that is, only these percentages of the participants hold biased perceptions.

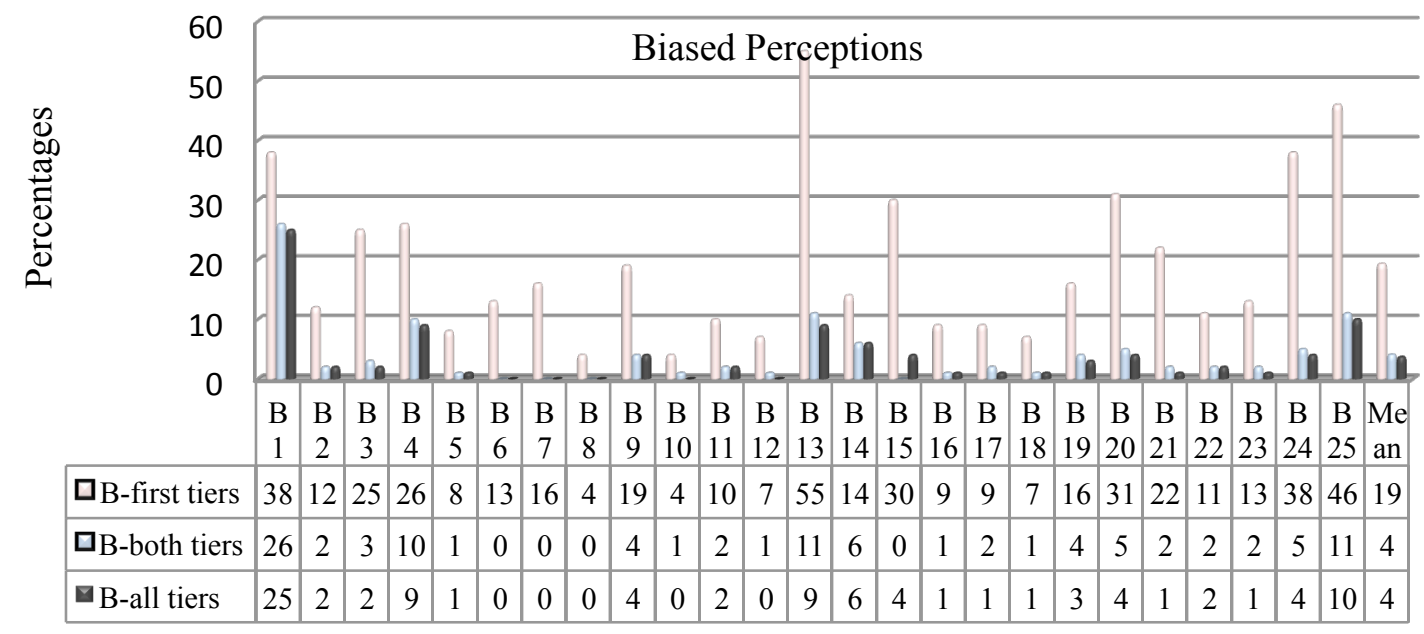

Figure 4. Percentages of biased-perceptions 
As seen from figure 4, if only B-first tier score were evaluated, we would conclude that $16 \%$ of nascent entrepreneurs hold biases about B7, however, when B-all tier score is considered, it is seen that none of the participants' hold this biased perception. It is obvious that certainty index has not a discriminating power for diagnosing second tiers from the third. Koellinger et. al. (2007) mentions that overconfidence in incorrect responses represents tenacious biased perception. The findings obtained from the test result justify the need to employ a tool identifying whether or not a wrong answer in the first tier is due to lack of knowledge or a biased perception, as well as whether or not a correct answer of the first tier is due to the participant's actually understanding the concept in social sciences too.

\section{Conclusion}

The LEDI has been developed as an assessment tool to diagnose biased perceptions of nascent entrepreneurs. The aim of entrepreneurship education is to introduce participants to the concepts of entrepreneurship so that, they can either establish their own start-ups or realize entrepreneurship is not suitable for them. However, if their pre-education beliefs on concepts is strong enough to persist after the education, then these beliefs should be addressed before the course. The use of LEDIlike instruments will help to differentiate the biased perceptions from lack of knowledge so it will shape entrepreneurship education.

A significant finding of LEDI has been that there is a prominent difference in using a single-tiered test versus a three-tiered test in diagnosing biased perceptions regarding entrepreneurship. If only a single-tiered test was used, we could have concluded, the mostly stated biased perception would be 'the ideal product/service targets everyone as its customer' because $55 \%$ of the respondents have selected this. However, when we ask the reasoning of this statement, only $11 \%$ of the participants continue with biased perception and when the third level of certainty is added merely 9 $\%$ hold on to their biased perception. The same reduction in the percentages happens with three other biased perceptions as well. Thus, the LEDI with its three-tiered structure sifts through the 'noise' at the first level and brings out the 'biased perceptions' at the third level.

The LEDI proves to be a valid and reliable instrument to diagnose biased perception issues on entrepreneurship through the LS approach. The findings of the present study reveal that some biased perceptions persist at the third level and some biased perceptions do not survive to the third level. As far as the noticeable biased perceptions are concerned, we find four after the third level of the LEDI. The first one is 'a fair distribution of shares among partners is equal share distribution'. This biased perception is reported to be observed among some sample of start-ups (Ruef, 2010). However, it is a biased perception because as Hellman and Wasserman (2012) report equal splits are correlated with slower growth and low external validation. Therefore, Hellman and Wasserman (2012) advise founders not to make their equity split decision early on in the start-up process and to take the time to consider the consequences of this split.

A second noticeable biased perception is the belief that 'a prototype should reflect the cutting edge technology'. Ahlstrom and Furr (2011) emphasizes for a start-up it is important to learn if the customer pain is addressed adequately with the product to be 
developed. Therefore, the prototype, should be a 'quick and minimal representation of what you plan to do'.

The third biased perception is that 'the ideal product/service targets everyone as its customer'. Blank (2016) warns potential entrepreneurs to search out the target customers who should be paid utmost attention so that their contentment brings on new customers. Aulet (2013) defines this group as 'beachhead market' (p.41) and emphasizes their importance for the entrepreneur to secure a 'beachhead' presence in enemy territory which later on leads to other segments.

The fourth biased perception is the one 'the main goal of an entrepreneur is to earn high income' (Wiklund et. al. 2008). Entrepreneurs' work should be performed full heartedly, because when work is done with devotion, it pays off in high sales revenue simply because it solves a problem elegantly.

The LEDI is the first attempt to apply a three-tiered instrument approach to entrepreneurship. This is a challenging task since entrepreneurship is a social science and there are no black/white issues in social sciences. Following the literature and expert opinions it is possible to reach generally accepted statements from which biased perceptions can be deduced. That is how the LEDI was developed. In the future, such instruments could be improved to include other biased perceptions regarding subsets of the LS approach such as the eight boxes of the business model canvas. Since we found overconfidence in the findings of the LEDI in this study which was applied to students, the LEDI could be improved by applying it to non-student nascent entrepreneurs. Furthermore, the certainty level may be measured via a Likert scale instead of a yes/no question. The LEDI could also be specialized according to technology-intensity or industry-type of issues in entrepreneurship. LEDI as a diagnostic tool for coming up with biased perceptions, entrepreneurship educators may employ its findings. 


\section{References}

Ajzen, I. 1991. "The Theory Of Planned Behavior". Organizational Behavior And Human Decision Processes 50 (2): 179-211. doi:10.1016/0749-5978(91)90020-t.

Aldrich, H.E. and Ruef, M. 2006 Organizations Evolving, London, Sage Publications.

Aldrich, H. E., Renzulli, L. and N. Langton. 1998. 'Passing on Privilege: Resources Provided by Self-employed Parents to their Self-employed Children.' pp. 291-317 in Kevin Leicht (ed.), Research in Social Stratification and Mobility. Greenwich, CT: JAI Press

Audretsch, D. B. Grilo, and AR Thurik. 2013. "Globalization, Entrepreneurship And The Region". In Handbook Of Research On Entrepreneurship And Regional Development, 1st ed., 11-32. Cheltenham: Edward Elgar.

Aulet, B., and Ursache. M. 2013. Disciplined Entrepreneurship. 1st ed. Hoboken, NJ: John Wiley \& Sons.

Blank, Steve. 2016. "How To Build A Startup: The Lean Launchpad | Udacity". Udacity.Com. https://www.udacity.com/course/how-to-build-a-startup--ep245.

Blank, Steve. 2013. "Why The Lean Startup Changes Everything". Harvard Business Review 91 (5): 63-72.

Blank, Steve. 2012. The Startup Owner's Manual. 1st ed. Cork: BookBaby.

Blenker, P., Frederiksen, S.H., Korsgaard S., Müller, S., Neergard, H., Thrane, C. 2012. Entrepreneurship as Everyday Practice: Towards a Personalized Pedagogy of Enterprise Education, Industry and Higher Education, 26(6): 417-430. https://doi.org/10.5367/ihe.2012.0126

Busenitz, Lowell W. and Jay B. Barney. 1997. 'Differences Between Entrepreneurs and Managers in Large Organizations: Biases and Heuristics in Strategic DecisionMaking.' Journal of Business Venturing, 12, 1 (January): 9-30.

Butt, Maheen, Nadia Jamil, and Rabia Nawaz. 2015. "The Mediating Role Of Risk Perception Among Cognitive Biases Towards Decision To Start A New Venture". International Letters of Social And Humanistic Sciences 54: 88-95. doi:10.18052/www.scipress.com/ilshs.54.88.

Cataloglu, E. 2002. "Development And Validation Of An Achievement Test In Introductory Quantum Mechanics: The Quantum Mechanics Visualization Instrument (QMVI)". PhD, The Pennsylvania State University.

Cooper, AC. 1986. Optimists And Pessimists: 2994 Entrepreneurs And Their Perceived Chances For Success. National Federation Of Independent Business. West Lafayette: Purdue University.

Cooper, Brant, and Patrick Vlaskovits. 2013. The Lean Entrepreneur. 1st ed. New Jersey: John Wiley and Sons.

Crocker, L, and J Algina. 1986. Introduction To Classical And Modern Test Theory. 1st ed. Orlando: Holt. 
Dunne, Timothy, Mark J. Roberts, and Larry Samuelson. 1988. "Patterns Of Firm Entry And Exit In U.S. Manufacturing Industries". The RAND Journal Of Economics 19 (4): 495. doi:10.2307/2555454.

Furr, Nathan R, and Paul B Ahlstrom. 2011. Nail It Then Scale It. 1st ed. [United States?]: Nathan Furr and Paul Ahlstrom.

Geroski, P.A. 1995. "What Do We Know About Entry?". International Journal Of Industrial Organization 13 (4): 421-440. doi:10.1016/0167-7187(95)00498-х.

Hasan, Saleem, Diola Bagayoko, and Ella L Kelley. 1999. "Misconceptions And The Certainty Of Response Index (CRI)". Physics Education 34 (5): 294-299. doi:10.1088/0031-9120/34/5/304.

Hellman, T, and N. Wasserman. 2012. "The First Deal: The Division Of Founder Equity In New Ventures". http://www.hbs.edu/faculty/Publication\%20Files/14085_2bd67a49-bd41-4396-a69d-73a7f40829b8.pdf.

Hestenes, David, and Ibrahim Halloun. 1995. "Interpreting The Force Concept Inventory: A Response To March 1995 Critique By Huffman And Heller". The Physics Teacher 33 (8): 502-502. doi:10.1119/1.2344278.

Jakopec, A, I Miljkovıć, and ZS Krečar. 2013. "Predictors Of Entrepreneurial Intentions Of Students Of Economics". Studia Psychologica 55 (4): 289-297.

Kahneman, Daniel, Paul Slovic, and Amos Tversky. 1982. Judgment Under Uncertainty: Heuristics and Biases. New York: Cambridge University Press.

Kautonen, Teemu, Marco van Gelderen, and Erno T. Tornikoski. 2013. "Predicting Entrepreneurial Behaviour: A Test Of The Theory Of Planned Behaviour". Applied Economics 45 (6): 697-707. doi:10.1080/00036846.2011.610750.

Kautonen, Teemu, Marco van Gelderen, and Matthias Fink. 2013. "Robustness Of The Theory Of Planned Behavior In Predicting Entrepreneurial Intentions And Actions". Entrepreneurship Theory And Practice 39 (3): 655-674. doi:10.1111/etap.12056.

Khan, Muhammad Umair, Akram Ahmad, Muhammad Fayyaz, Nida Ashraf, and Akshaya Bhagavathula. 2016. "Exploring The Intentions Of Pharmacy Students Towards Pharmacy Ownership By Using Theory Of Planned Behaviour". BMC Research Notes 9 (1). doi:10.1186/s13104-016-1996-4.

Krueger, Norris F., Michael D. Reilly, and Alan L. Carsrud. 2000. "Competing Models Of Entrepreneurial Intentions". Journal Of Business Venturing 15 (5-6): 411-432. doi:10.1016/s0883-9026(98)00033-0.

Lazear, Edward P. 2004. "Balanced Skills And Entrepreneurship". American Economic Review 94 (2): 208-211. doi:10.1257/0002828041301425.

Liao, Jianwen (Jon), and Harold Welsch. 2008. "Patterns Of Venture Gestation Process: Exploring The Differences Between Tech And Non-Tech Nascent Entrepreneurs". The Journal Of High Technology Management Research 19 (2): 103-113. doi:10.1016/j.hitech.2008.10.003.

Liñán, Francisco, and Yi-Wen Chen. 2009. "Development And Cross-Cultural Application Of A Specific Instrument To Measure Entrepreneurial Intentions". 
Entrepreneurship Theory And Practice 33 (3): 593-617. doi:10.1111/j.15406520.2009.00318.x.

Matlay, Harry. 2005. "Researching Entrepreneurship And Education". Education + Training 47 (8/9): 665-677. doi:10.1108/00400910510633198.

Minniti, Maria. 2005. "Entrepreneurship And Network Externalities". Journal Of Economic Behavior \& Organization 57 (1): 1-27. doi:10.1016/j.jebo.2004.10.002.

Mungal, Avika, and Hari Lall Garbharran. 2014. "The Perceptions Of Small Businesses In The Implementation Of Cash Management Techniques". Journal Of Economics And Behavioral Studies 6 (1): 75-83. doi:10.5901/mjss.2014.v5n27p11.

Muofhe, Nnditsheni J., and Willem F. Du Toit. 2011. "Entrepreneurial Education's And Entrepreneurial Role Models' Influence On Career Choice". SA Journal Of Human Resource Management 9 (1). doi:10.4102/sajhrm.v9i1.345.

Noel, TW. 2002. "Effects Of Entrepreneurial Education On Intent To Open A Business: An Exploratory Study". The Journal Of Entrepreneurship Education 5: 3-13.

Obschonka, Martin, Maximilian Goethner, Rainer K. Silbereisen, and Uwe Cantner. 2012. "Social Identity And The Transition To Entrepreneurship: The Role Of Group Identification With Workplace Peers". Journal Of Vocational Behavior 80 (1): 137-147. doi:10.1016/j.jvb.2011.05.007.

Odom, Arthur L., and Lloyd H. Barrow. 2007. "High School Biology Students' Knowledge And Certainty About Diffusion And Osmosis Concepts". School Science And Mathematics 107 (3): 94-101. doi:10.1111/j.19498594.2007.tb17775.x.

Ogunsade, Isaac A., and Demola Obembe. 2016. "The Influence Of Informal Institutions On Informal Sector Entrepreneurship: A Study Of Nigeria's HandWoven Textile Industry". Journal Of Small Business \& Entrepreneurship 28 (6): 413-429. doi:10.1080/08276331.2016.1202093.

Osterwalder, Alexander, Yves Pigneur, Greg Bernarda, and Alan Smith. 2014. Value Proposition Design. 1st ed. New Jersey: John Wiley \& Sons.

Pallier, G, R Wilkinson, V Danthiir, S Kleitman, Z Knezevic, L Stankov, and RD Roberts. 2002. "The Role Of Individual Differences In The Accuracy Of Confidence Judgments". Journal Of General Psychology 129 (3): 257-299.

Ries, Eric. 2011. The Lean Startup: How Today's Entrepreneurs Use Continuous Innovation To Create Radically Successful Businesses.. 1st ed. Crown Publishing.

Ruef, M. 2010. The Entrepreneurial Group: Social Identities, Relations And Collective Action. 1st ed. Princeton: Princeton University Press.

Samwel Mwasalwiba, Ernest. 2010. "Entrepreneurship Education: A Review Of Its Objectives, Teaching Methods, And Impact Indicators". Education + Training 52 (1): 20-47. doi:10.1108/00400911011017663.

Schlaegel, Christopher, and Michael Koenig. 2013. "Determinants Of Entrepreneurial Intent: A Meta-Analytic Test And Integration Of Competing Models". Entrepreneurship Theory And Practice 38 (2): 291-332. doi:10.1111/etap.12087. 
Shook, Christopher L., and Constantin Bratianu. 2008. "Entrepreneurial Intent In A Transitional Economy: An Application Of The Theory Of Planned Behavior To Romanian Students". International Entrepreneurship And Management Journal 6 (3): 231-247. doi:10.1007/s11365-008-0091-2.

Timmons, JA. 1979. "Careful Self-Analysis And Team Assessment Can Aid Entrepreneurs". Harvard Business Review Nov-Dec: 198-206.

Treagust, David F. 1988. "Development And Use Of Diagnostic Tests To Evaluate Students' Misconceptions In Science". International Journal Of Science Education 10 (2): 159-169. doi:10.1080/0950069880100204.

Varamaki, Elina, Joensuu, Sanna, Viljamaa, Anmari, 2016, Starting up a firm or not

Differences in the antecedents of entrepreneurial intentions, Industry and Higher Education 30(3) 239-249. https://doi.org/10.1177/0950422216655046

von Graevenitz, G., Dietmar Harhoff, and R Weber. 2010. "The Effects Of Entrepreneurship Education". Journal Of Economic Behavior And Organization 76 (1): 90-112. doi:10.2139/ssrn.1445085.

Wiklund, Johan, Per Davidsson, and Frédéric Delmar. 2008. "What Do They Think And Feel About Growth? An Expectancy-Value Approach To Small Business Managers' Attitudes Toward Growth". Entrepreneurship Theory And Practice 27 (3): 247-270. doi:10.1111/1540-8520.00014.

Williams Middleton, Karen, and Anne Donnellon. 2014. "Personalizing Entrepreneurial Learning: A Pedagogy For Facilitating The Know Why". Entrepreneurship Research Journal 4 (2). doi:10.1515/erj-2013-0040.

Würmseher, Martin. 2017. "To Each His Own: Matching Different Entrepreneurial Models To The Academic Scientist's Individual Needs". Technovation 59: 1-17. doi:10.1016/j.technovation.2016.10.002.

Zhang, Pingying, Dongyuan D. Wang, and Crystal L. Owen. 2015. "A Study Of Entrepreneurial Intention Of University Students". Entrepreneurship Research Journal 5 (1). doi:10.1515/erj-2014-0004. 